Special issue of the 3rd International Conference on Computational and Experimental Science and Engineering (ICCESEN 2016)

\title{
Development of a Low Noise and Low Energy Consumption Alpha Spectroscopy Amplifier for ${ }^{222}$ Rn Gas Detection
}

\author{
M.F. KuluÖZTÜRK ${ }^{a, *}$, S. ÖZGEN ${ }^{b}$ AND M. DOĞRU ${ }^{b}$ \\ ${ }^{a}$ Bitlis Eren University, Electrical-Electronics Engineering Department, Bitlis, Turkey \\ ${ }^{b}$ Frrat University, Physics Department, Elazığ, Turkey
}

\begin{abstract}
${ }^{222} \mathrm{Rn}$ gas is a member of ${ }^{238} \mathrm{U}$ decay chain, which is the most abundant in nature, and decays by releasing alpha particles with energy of $5.49 \mathrm{MeV}$. Various detection systems are used for radon gas detection in the research of natural radioactivity, health, geophysics etc. The detection systems need some electronics layers, like amplifier, analyser and data storage unit. These systems generally use mains voltage or self-battery and they are not useful for long-term field research because of energy consumption, which is relatively high. In this study, the development of a low energy consumption and low noise spectroscopy amplifier system for the detection of $\alpha$ radiation emitted by ${ }^{222} \mathrm{Rn}$ and its daughters is presented. Amplifying and pulse shaping stages were developed with nuclear electronic methods. Operating performance of amplifying and pulse shaping stages has been demonstrated with a series of electronic and radioactive tests (gain test, signal to noise ratio measurement, electronics calibration and energy calibration). Additionally, nuclear spectroscopic studies were performed for comparison of this system with other alpha spectroscopy systems.
\end{abstract}

DOI: 10.12693/APhysPolA.132.789

PACS/topics: 29.30.Aj

\section{Introduction}

Radon is a colourless, odourless, tasteless and radioactive noble gas. It is the only gas product of three natural decay chains. Radon decays to ${ }^{218} \mathrm{Po}$ (3.82 days half-life) by emitting alpha particles with energy of $5.49 \mathrm{MeV}$ [1]. It constitutes $55 \%$ of the natural radioactivity. Radon products $\left({ }^{218} \mathrm{Po},{ }^{214} \mathrm{~Pb},{ }^{214} \mathrm{Bi},{ }^{214} \mathrm{Po}\right)$ decay by alpha, beta and gamma decay with half-life values ranging between $1.5 \times 10^{-4}$ seconds and 26.8 minutes. Alpha radiation, which is released by radon gas or its decay product ${ }^{214} \mathrm{Po}$ is generally used for the detection of radon [2].

There are many methods used for radon detection. Commonly used methods are passive solid state nuclear track detectors (SSNTDs) [1, 3], gas filled detectors [4] and lithium drifted silicon detectors $[5,6]$. Silicon detectors and gas filled detectors require some electronic layers: pre-amplifier (PA), pulse shaping amplifier (PSA), analog to digital converter (ADC) and counter [7, 8].

In this study, a charge sensitive amplification stage (PA, PSA) was developed by using nuclear electronics methods. The main objectives of the amplifier are low noise, low energy consumption, biasing by a battery and small dimensions. The electronic amplifier board was developed using DipTrace PCB - a computer design software for creating printed circuit boards $(\mathrm{PCB})$ and, subsequently, the printed circuit was populated with surface mount device (SMD) circuit components. A series of tests were performed for the description of the

*corresponding author; e-mail: mfkuluozturk@beu.edu.tr electronic and nuclear performance of the amplifier (gain test, signal to noise ratio (SNR) measurement, electronics calibration, full width at half maximum (FWHM) measurements and energy calibration). Additionally the same tests were performed with a professional Nuclear Instrumentation Module (NIM) spectroscopy system for comparison.

\section{Methods}

\subsection{Electronics of spectroscopy amplifier}

The PA and PSA circuits were designed in PCB layout Dip-Trace software (Fig. 1). Two TLE2022 SMD units were used in the circuit, which were supplied by $5 \mathrm{~V}$ DC external voltage. The detector bias voltage was also supplied by external $12 \mathrm{~V}$ DC voltage. The designed spectroscopy amplifier was named FUAMP. An ion implanted silicon detector for charged particles (U-019300-100) by ORTEC was used as detector.
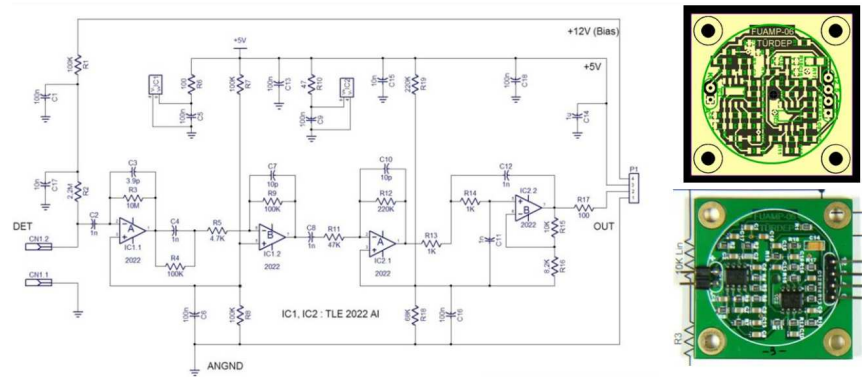

Fig. 1. Amplifier circuit scheme, printed circuit design and populated board.

When radiation interacts with the detector, a decrease in the detector voltage occurs. This signal is firstly 
amplified in the charge sensitive preamplifier. Then CR shaping is applied to the preamp output signal to obtain a gaussian pulse. After the CR shaping, two differential amplifiers and second order Butterworth low pass filter layers were placed.

The PCB has dimensions of $3.5 \mathrm{~cm} \times 3.5 \mathrm{~cm}$. The spectroscopy amplifier circuit has two gold-plated pins on the front side for the detector and four pins on the back side for the $+12 \mathrm{~V}$ detector bias, $+5 \mathrm{~V}$ circuit bias, analog signal output and GND.

A number of tests and measurements (gain test, SNR measurement, electronics calibration, FWHM measurements and energy calibration) were performed to determine the performance of the spectroscopy amplifier circuit after its installation. The same measurements and tests were carried out using a commercial standard alpha spectroscopy system (ORTEC, Model-142 Preamplifier and Model-672 Spectroscopy Amplifier) and then comparisons were made.

\subsection{Tests and measurements}

Gain test was performed by adding a $1 \mathrm{pF}$ capacitor and $50 \Omega$ resistor to the detector input of the spectroscopy amplifier used for simulation of the detector [9]. Gain was calculated as the ratio of output to input signal voltage. Input signal voltage was generated by Keithley 3390 arbitrary function generator. Additionally the spectroscopy amplifier system can be electronically calibrated with this setup. If a known capacity $(1 \mathrm{pF})$ simulates the detector and an energy of $3.62 \mathrm{eV}$ is necessary for an electron-hole pair production in silicon, then the input voltage value can be calculated and, by using the gain value, energy values can be assigned to the output voltages [10].

SNR measurements, FWHM measurements, energy calibration and efficiency calibration were performed on an experimental setup that consisted of vacuum pump, vacuum chamber, standard alpha sources $\left({ }^{237} \mathrm{~Np},{ }^{239} \mathrm{Pu}\right.$, $\left.{ }^{241} \mathrm{Am},{ }^{244} \mathrm{Cm}\right)$, ion implanted silicon charged particle detector, DC power supply and oscilloscope (Fig. 2).

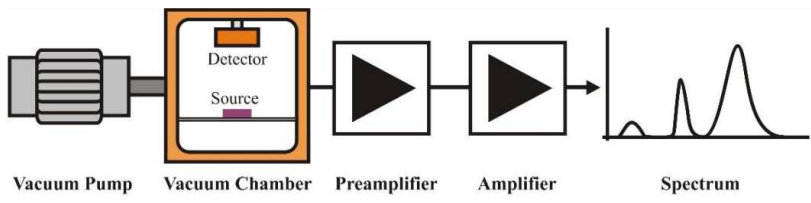

Fig. 2. Experimental setup scheme for measurements and calibrations.

Gain tests were performed by measuring the output voltages versus variable input voltages. Gain and electronic calibration of FUAMP was plotted and gain function was generated (Fig. 3).

The SNR amplitudes were measured from the output signal of our spectroscopy amplifier by using an oscilloscope and then the SNR values were calculated in decibels (dB) [11]. The commercial spectroscopy amplifier

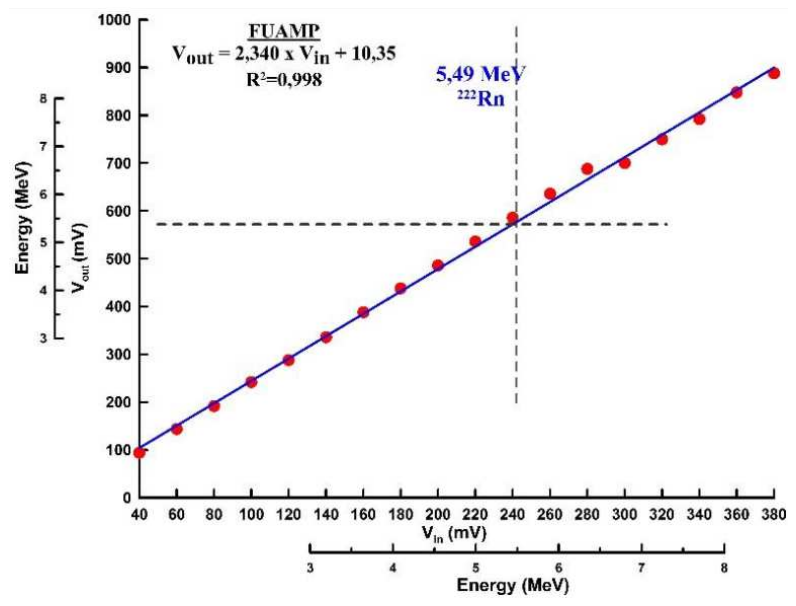

Fig. 3. Gain and electronic calibration of FUAMP spectroscopy amplifiers.

has approximately $10 \%$ better SNR values than FUAMP (see Table. 1). FWHM values were determined for each energy peak in the spectra. The commercial amplifier has generally better FWHM (see Table I).

TABLE I

FWHM and SNR measurement results.

\begin{tabular}{|c|c|c|c|c|c|}
\hline & \multicolumn{4}{|c|}{ Energy $[\mathrm{MeV}]$} & \multirow[b]{2}{*}{$\mathrm{SNR}_{d B}$} \\
\hline & $\begin{array}{c}4.788 \\
\left({ }^{237} \mathrm{~Np}\right)\end{array}$ & $\begin{array}{c}5.157 \\
\left({ }^{239} \mathrm{Pu}\right)\end{array}$ & $\begin{array}{c}5.486 \\
\left({ }^{241} \mathrm{Am}\right)\end{array}$ & $\begin{array}{c}5.902 \\
\left({ }^{244} \mathrm{Cm}\right)\end{array}$ & \\
\hline ORTEC & 86.84 & 77.81 & 110.84 & 61.04 & 24.695 \\
\hline FUAMP & 104.32 & 110.57 & 107.25 & 90.21 & 22.452 \\
\hline
\end{tabular}

Energy calibrations were made using spectra from each of the standard alpha sources placed in $25 \times 10^{-6}$ atm vacuum (Fig. 4). Additionally spectra were obtained by counts with all of the standard alpha sources acting simultaneously in vacuum (Fig. 5).

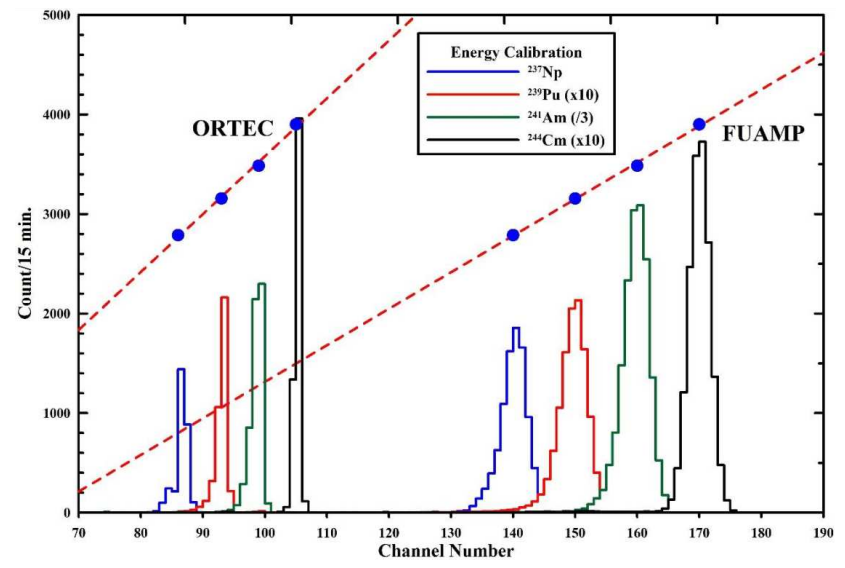

Fig. 4. Energy calibrations of FUAMP and ORTEC spectroscopy amplifiers. 


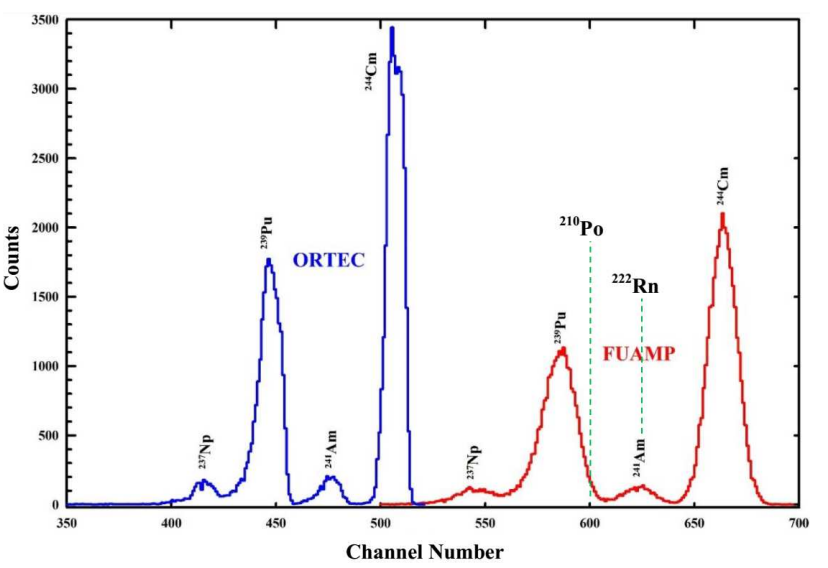

Fig. 5. Spectra from FUAMP and ORTEC spectroscopy amplifiers by using standard alpha sources in vacuum.

\section{Conclusions}

The commercial equivalent system ORTEC, which is compared to the developed FUAMP spetroscopic amplifier, uses mains voltage in laboratory and it is manufactured for use in precision alpha spectroscopy studies. In contrast the FUAMP system is designed for long-term, outdoor, radon gas detection. FUAMP has a number of advantages and disadvantages due to differences in application area.

The performance of FUAMP spectroscopy amplifier is close to the performance of the professional commercial instrument. In Fig. 5 it is shown that commercial system has better FWHM and efficiency than FUAMP. However FUAMP has good enough energy resolution to distinguish between ${ }^{222} \mathrm{Rn}(5.489 \mathrm{MeV})$ and its decay product ${ }^{210} \mathrm{Po}(5.304 \mathrm{MeV})$ (Fig. 5). The SNR value of the FUAMP spectroscopic amplifier system is worse than that of ORTEC system. As the SNR ratio is a factor directly affecting the FWHM value, increasing this ratio will also improve the FWHM value. When FWHM, which is a measure of energy resolution, is improved, it will be easier to distinguish closely adjacent peaks.

Another disadvantage is that the gain value is not adjustable. When it will be desired to make changes in the FUAMP, which will be part of a system for outdoor work, it will be necessary to intervene in the circuit elements. This is not useful. However, adding a digital potentiometer that allows such adjustments to be made, will allow to change the gain values via the software. Finally, a test input with a capacitance of $1 \mathrm{pF}$ connected to the detector input must be added, so that the necessary tests can be performed.
The advantages of FUAMP: low voltage requirement $(12 \mathrm{~V})$, low energy consumption (1.2 $\mathrm{mA}$ in operating mode), low dimensions and low cost. The $12 \mathrm{~V}$ voltage requirement can be provided by small portable batteries or by using a voltage rectifier device from the mains voltage. In addition, thanks to low energy consumption in the operating mode, it has the advantage of being able to work outdoor for long-term without the need for mains voltage. The small size design of $3.5 \mathrm{~cm} \times 3.5 \mathrm{~cm}$ can be converted into a circular shape with a diameter of $3 \mathrm{~cm}$, if desired. These small dimensions will take up little space in the radon detector to be designed, or it will be possible to insert it into a probe. Finally, the cost of FUAMP is very low. Due to these features, FUAMP is suitable for long-term outdoor measurements.

\section{Acknowledgments}

This study was supported by "Türkiye'nin Deprem Riski Yüksek Jeo-Stratejik - Ancak Tektonik Rejimleri Farklı-Bölgelerinde Deprem Davranışının Çok Disiplinli Yaklaşımlarla Araştırılması" TUBİTAK (The Scientific and Technological Research Council of Turkey) project, (project number: 5057001).

\section{References}

[1] S. Durrani, R. İliç, Radon Measurements by Etched Track Dedectors: Applications in Radiation Protection. Earth Sciences and the Environment, World Scientific, New Jersey 1997, p. 387.

[2] A. Fişne, G. Ökten, N. Çelebi, in: Proc. 14th Turkey Coal Congress, Zonguldak 2004, p. 190.

[3] A. Kahraman, A. Poffijn, G. Kaynak, Acta Phys. Pol. A 125, 268 (2014).

[4] F. Kulalı, I. Akkurt, Acta Phys. Pol. A 128, B-445 (2015).

[5] F. Ertuğral, H. Yakut, E. Tabar, R. Akkaya, N. Demirci, Z. Zenginerler, Acta Phys. Pol. A 128, B-251 (2015).

[6] M. İçhedef, M.M. Saç, C. Harmanşah, C. Taskopru, Appl. Radiat. Isotop. 86, 102 (2014).

[7] A. Bayrak, E. Barlas, E. Emirhan, Ç. Kutlu, C.S. Ozben, Appl. Radiat. Isotop. 78, 1 (2013).

[8] N. Tsoulfanidis, Measurement and Detection of Radiation, Taylor \& Francis, Washington 1995.

[9] ORTEC, Preamplifiers, www.ortec-online.com//media/ametekortec/other/preamplifierintroduction.pdf?la (15.10.2016).

[10] IAEA, Nuclear Electronics Laboratory Manual, International Atomic Energy Agency, Vienna 1989.

[11] D.J. Schroeder, Astronomical optics, 2nd ed., Academic Press, California 1999. 